\title{
LXXX. On extremely long waves, emitted by the quartz mercury lamp
}

\section{H. Rubens \& O. von Baeyer}

To cite this article: $\mathrm{H}$. Rubens \& O. von Baeyer (1911) LXXX. On extremely long waves, emitted by the quartz mercury lamp , Philosophical Magazine Series 6, 21:125, 689-695, DOI: $10.1080 / 14786440508637081$

To link to this article: http://dx.doi.org/10.1080/14786440508637081

册 Published online: 21 Apr 2009.

Submit your article to this journal $\lceil\pi$

Џ Article views: 8

Q View related articles $\square$

Citing articles: 15 View citing articles 4 


\section{$\left[\begin{array}{lll}6 & 689 & \end{array}\right]$}

LXXX. On Extremely Long Waves, emitled by the Quartz Mercury Lamp. By H. Rubens and O. von BaEYeR*.

A $\mathrm{N}$ advance in the spectrum towards the side of the long A waves is extremely difficult, while using pure thermoradiators. If the source of heat does not possess selective qualities, the intensity of radiation in the long-waved spectrum diminishes with the 4 th power of the wave-length. It is true this intensity of radiation grows in proportion to the temperature of the source; but in a much higher degree (with the 4th power of the absolute temperature) the tutal energy of the radiant body augments, from which the desired part of radiation must be sorted out by certain processes. An increase of the temperature of the source of light will, therefore, in many cases scarcely involve an advantage for the present purpose. In the long-waved spectrum the Welsbach mantle has proved the most advantageous source of heat of purely thermoradiant character, because of its very favourable selective qualities. But even here, no rays of much greater wave-length than $108 \mu$ have been obtained.

This paper gives a description of experiments undertaken with a view to enlarge the knowledge of the infra-red spectral region, by employment of sources of light, from which the radiation is emitied by incandescent gases. As far as pure radiation of temperature is concerned, such lightsources are selective in the highest degree. Besides, the possibility of an existing long-waved infra-red luminescence radiation must here be considered.

Our arrangement of apparatus is identical with that used recently by $R$. W. Wood and one of us for the isolation of long-waved rays $\dagger$. It is founded on the use of quartz-lenses, which, because of the extreme difference of the index of refraction for heat-rays on both sides of the region of absorption in quartz (1.50 to 2.11 ), can be so adjusted as to concentrate the emitted long-waved radiation on a given diaphragm, while the ordinary heat-waves are dispersed. Our method is further founded on the selective absorption of quartz and on the effect of certain central screens. For all details concerning the apparatus and the method reference must be made to the above-cited paper.

The first sources of light we now used were strong leydenjar sparks between electrodes of zinc, cadmium, aluminium, iron, platinum, and bismuth ; the sparks were produced by a

* Communicated by the Authors.

$\dagger$ H. Rubens \& R. W. Wood, Phil. Mag. Feb. 1911. 


\section{Profs. H. Rubens and O. von Bacyer on Extremely}

$40 \mathrm{~cm}$. inductor, using alternating current for the inner coil. We have, however, in no case succeeded in obtaining a perceptible radiation in the observed long-waved spectral region. As little success was gained when we used the electric arc with carbon electrodes, or with Bremer carbons and carbons with iron-salt filling, if the investigation was limited to the electric arc itself. It is true, in both these last-named cases our micro-radiometer always showed small irregular deviations, which undoubtedly were due to long-waved radiation; but it is not improbable that this radiation is emitted by solid particles in the electric arc. The observed effects were neither regular enough nor sufficiently strong to allow of a closer investigation.

A comparatively very strong long-waved radiation was, however, obtained with the quartz-mercury lamp, especially at higher consumption of energy *. With a current of 4 amperes on 100 volts, the arc being about $80 \mathrm{~mm}$. long, a deflexion of more than $50 \mathrm{~mm}$. appeared in our micro-radiometer. When the lamp had burned some time this deviation proved so constant that it could easily be measured down to fractions of a per cent.

A few preliminary experiments showed us that the observed long-waved radiation of the mercury-lamp must possess it composition essentially different from that of the Welsbach mantle, the mean wave-length of which had, under the same conditions, amounted to $108 \mu$. We fonnd, for instance, that

\begin{tabular}{|c|c|c|c|c|c|}
\hline Substance. & $\begin{array}{c}d . \\
\text { mill. }\end{array}$ & $\begin{array}{c}\mathrm{D}_{\mathrm{r}} \\
\text { Per cent. }\end{array}$ & $\begin{array}{c}D_{2^{*}} \\
\text { Pet* cent. }\end{array}$ & $\begin{array}{c}\mathrm{D}_{3} \\
\text { Per cent. }\end{array}$ & $\begin{array}{c}\mathrm{D}_{4 \cdot} \\
\text { Per cent. }\end{array}$ \\
\hline Quartz & 41.7 & $12 \cdot 1$ & $25 \cdot 4$ & $51 \cdot 8$ & $58 \cdot 9$ \\
\hline Ainorphous quartz & 200 & $12 \%$ & $24 \cdot 2$ & - & 600 \\
\hline Fluorite ................... & 0.59 & $5 \cdot 3$ & $19 \cdot 4$ & 39.5 & $42 \cdot 2$ \\
\hline Rock-salt $\ldots . .$. & $1 \cdot 29$ & 0.5 & $5 \cdot 7$ & $16 \cdot 5$ & $2: 2 \cdot 5$ \\
\hline Sylvine ....... & $2 \cdot 10$ & 0 & $3 \cdot 6$ & $11 \cdot 7$ & $16 \cdot 7$ \\
\hline Dianond & $1 \cdot 26$ & 453 & $6+5$ & & - \\
\hline Selenium $\quad . . . . . . . .$. & 0.52 & $6 \cdot 8$ & 129 & $24 \cdot 2$ & - \\
\hline Mica $\ldots \ldots \ldots \ldots \ldots \ldots$ & 0.055 & $16 \cdot 6$ & $38 \cdot 8$ & $51 \cdot 5$ & $55 \cdot 0$ \\
\hline Glass .................. & $0 \cdot 18$ & $2 \cdot 1$ & 90 & $21 \cdot 1$ & 259 \\
\hline Paraffin ................... & 303 & 57.0 & $72 \cdot 3$ & $82 \cdot 5$ & 85.5 \\
\hline Hard rubber ........ & 0.40 & $39 \cdot 0$ & $51 \cdot 5$ & 588 & 653 \\
\hline Amber $\ldots \ldots \ldots \ldots \ldots$ & 1.28 & 112 & $16 \cdot 4$ & $32 \cdot 2$ & $34 \cdot 8$ \\
\hline Wood............. & $1 \cdot 80$ & $0 \cdot 7$ & 29 & $10^{\circ} 0$ & - \\
\hline Black Paper ....... & 0.11 & 335 & 524 & $78 \cdot 5$ & $79 \cdot 0$ \\
\hline Black Cardboard & 0.38 & $2 \cdot 1$ & 117 & $29 \cdot 8$ & 367 \\
\hline Celluloid........ & 0.26 & $16 \cdot 2$ & $27 \cdot 6$ & $38 \cdot 7$ & $43 \cdot 5$ \\
\hline Water & $\begin{array}{l}0.019 \\
0.038\end{array}$ & 20 & $\begin{array}{l}5.5 \\
33 \cdot 0\end{array}$ & $\begin{array}{l}6115 \\
38.4\end{array}$ & $\begin{array}{l}627 \\
39.8\end{array}$ \\
\hline
\end{tabular}

* A mercury-amalgam lamp, containing 20 per cent. bismuth and 20 per cent. lead on 60 per cent. mercury gave nearly the same results. 
a $14.66 \mathrm{~mm}$. thick layer of quartz transmitted $46 \cdot 6$ per cent. of the isolated radiation, when the mercury-lamp served as source of light; and only 21.7 per cent. when the Welsbach mantle was adopted as radiation-source.

This table shows, for a large number of substances, the transmission of long-waved radiation isolated by means of quartz-lenses. Both sources of light were in use, $\mathrm{D}_{1}$ being the transmission observed with the Welsbach mantle, $\mathrm{D}_{2}$ with the mercury-lamp as radiator. We have, moreover (under $\mathrm{D}_{3}$ ), exhibited, for the same substances, the transmission of the radiation of the mercury-lamp filtered by a $2.0 \mathrm{~mm}$. thick layer of amorphous quartz. It could be assumed from the beginning that the observed radiation of the mercurylamp consisted of two parts, one of which emanated from the hot quartz-walls of the tube, the other from the mercury vapour itself. For the separation of the latter part we at first deemed a filter of melted quartz most suitable. Later on, we found that a ray-filter of black cardboard proved still more efficient for the isolation of the long-waved radiation emerging trom the mercury vapour. In the last column of our table $\left(D_{4}\right)$ we have therefore exhibited the results of the measurements on transmission, obtained after substituting a filter of black cardboard, $0.38 \mathrm{~mm}$. thick, for the amorphous quartz.

By reference to the table it will immediately be seen that for all substances the values $\mathrm{D}_{1}, \mathrm{D}_{2}, \mathrm{D}_{3}$, and $\mathrm{D}_{4}$ form an ascending series. So far as substances are concerned whose region of absorption is known to be situated af shorter wavelengths (as quartz, fluorite, rock-salt, and sylvine), this course indicates an increase of the mean wave-lengths of the corresponding radiations. We must therefore attribute a greater mean wave-length to this radiation of the mercurylamp than to that emitted by the Welsbach mantle; we must further assume a greater mean wave-length for the radiation of the mercury-lamp filtered by black cardboard, than for that which passed through amorphous quartz. This assumption is in a still higher degree justified by the behaviour of black paper and black cardboard, because in such media, in which the principal loss of energy is due to diffuse dissipation, the transmission must strongly increase with growing wavelength. The rise of the mean wave-length, which the radiation of the mercury-lamp shows after the introduction of the radiation-filters employed, is according to our opinion due to the fact that the short-waved radiation of the quartz-tube (which is nearly of the same quality with that of the Welsbach mantle) is much more strongly absorbed by these filters than 


\section{Profs. H. Rubens and $\mathrm{O}$. von Baeyer on Eatremely}

the evidently much longer-waved radiation of the mercury vapour. The extremely high transmission of quartz is of particular interest for these kinds of radiation. On calculating the coefficient of absorption

$$
q_{r}=\frac{1}{d} \log \text { nat. } \frac{100}{\mathbf{D}_{r}{ }^{\prime}}
$$

from the transmission for the $41.7 \mathrm{~mm}$. thick quartz plate, cut perpendicularly to the axis ( $d$ being the thickness of the plate in $\mathrm{mm}, \mathrm{D}_{r}{ }^{\prime}$ the transmission, corrected on account of the loss by reflexion), we obtain for the here investigated riadiations the following values of $q_{r}$ :-

$$
q_{1}=0.044 ; q_{2}=0.026 ; q_{3}=0.0089 ; q_{4}=0.0057 \text {. }
$$

It is evident that the rays of the mercury-lamp filtered by black cardboard must penetrate about 8 times as thick a quartz-layer as the rays emerging from the Welsbach mantle, before being attenuated to the same fraction of their primary intensity. Similar circumstances prevail with amorphous quartz, but here the absorption-power for the four investigated radiations is about 20 times as great as at the natural modification.

Glass and mica seem, like fluorite, rock-salt, and sylvine, to belong to the substances whose main region of absorption lies among the wave-lengths below $100 \mu$. The high transmission of paraffin, hard rubber, and amber, well-known as good isolators, is not surprising; neither is the small absorption of the elements diamond and selenium.

Water shows a far smaller absorption power for the radiation emitted by the mercury-lamp (particularly after its filtration through quartz or black cardboard) than for the rays emanating from the Welsbach mantle. The reflexion from the water surfaces can also not be considerable, as the values of the coefficient of absorption calculated from both layers of different thickness agree satisfactorily without consideration of the reflecting power. This would not be so in case of a considerable loss by reflexion. We may, therefore, assume that in these spectral regions water still possesses a refractive index of small magnitude, lying far closer to the value observed in the visible spectrum than to the squareroot of the dielectric constant for slow vibrations.

As our measurements of absorption cannot give quantitative determinations as to the average wave-length of the investigated radiations, we have attempted to measure the wave-length by aid of the previously employed interferometer*. The interference-curves obtained with the

* H. Rubens \& H. Hollnagel, Phil. Mag. [6] xix. p. 781 (1910). 
Long Wuves emitted by the Quartz Mercury Lamp. 693 quartz-mercury lamp-omitting the radiation filter-showed very irregular character. Nevertheless, it was evident that the main element of the investigated radiation was supplied by a radiation of about the same mean wave-length as that resulting from the Welsbach mantle with this arrangement. But as soon as a $15 \mathrm{~mm}$. thick layer of quartz was inserted, the aspect was changed. The first minimum, which had been observed for unfiltered radiation at a thickness of the air-film of about 5 divisions of the drum * $(26 \mu)$, now did not appear before a thickness of the layer of air of 8 divisions $(42 \mu)$. If the thickness of the inserted layer of quartz was increased to $42 \mathrm{~mm}$, the first minimum appeared only at a distance of the interferometer plates of about 13 divisions $(68 \mu)$. At the same time the interference curve showed a much smoother course. The originally observed irregular maxima and minima had nearly quite disappeared; and, besides the mentioned minimum at 13 divisions, in some series of observations a faintly marked maximum appeared in

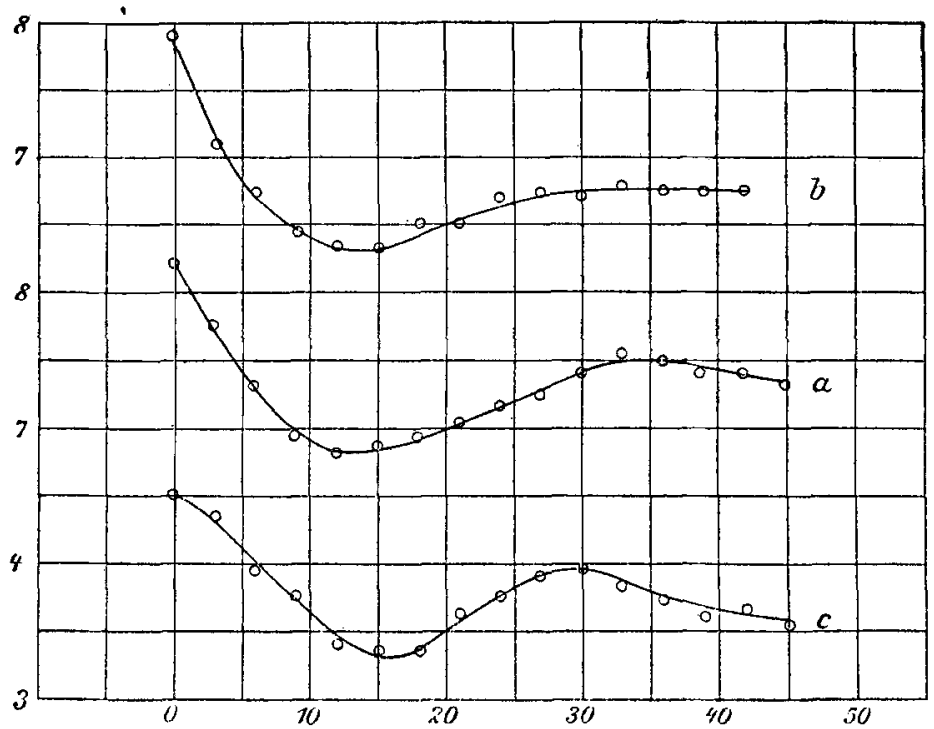

the further course of the curve. Such an interferometercurve is exlibited in the accompanying figure (curve $a$ ). Curve $(b)$ of the same figure was observed in the same way with insertion of the $2 \mathbf{m m}$. thick plate of amorphous quartz; curve $(c)$ with insertion of the black cardboard $(0.4 \mathrm{~mm}$. thick). Curve (c) shows the wave-character most distinctly. Here the minimum lies at 15 divisions $(78.4 \mu)$ and the

* One division of the drum to $5.23 \mu$. 


\section{Long Waces emitted by the Quartz Mercury Lamp.}

maximum at 30 is more conspicuous than in the other curves. But even in this curve an accurate delermination of these points is very difficult. The assumption is certainly justifiable, that the radiation filtered through black cardboard contains a greater amount of this long-waved part than it does after purification by the quartz-filter. We had already deduced this fact from the results of the absorption-table.

It is still an open question, whether this long-waved radiation consists of several nearly homogeneous kinds of rays of different wave-length-as would be expected upon the assumption of a luminiferous radiation of mercury vapour -or whether it is a continuous radiation, covering a larger spectral region, such as thermo-radiators mostly possess. The results of the interferometer measurements are unable to warrant us in settling this question. But we can safely deduce from our observations, that a large part of this radiation emerging from the quartz-mercury lamp possesses a mean wave-length of about $30 \times 2 \times 5 \cdot 23 \mu=314 \mu$ or nearly $\frac{1}{3} \mathrm{~mm}$.

With a view to confirming our supposition, that this extremely long-waved radiation originates in the mercury vapour itself and not in the hot quartz-tube of the lamp, we cite the following reflection:-As the intensity of the radiation from a black body diminishes with the 4 th power in the region of great wave-lengths, amorphous quartz (which at $\lambda=100 \mu$ behaves nearly like a black body) might at the threefold wave-length send forth at most the 81 st part of the energy ii emits at $100 \mu$. But at the relatively low temperature of the quartz-mantle such a feeble radiation would not be discernible. We could, moreover, show by experiment that the observed long-waved radiation came from the mercury vapour itself. The intensity of radiation was measured shortly before and after the break of the current of the lamp. On introduction of the cardboard-filter the observed intensity of radiation fell, immediately after the interruption of the current, to about 30 per cent. of the initial value, and then slowly diminished more and more. The same experiment without cardboard-filter only produced a decrease of radiation of about 30 per cent. after the interruption of the lamp-current. We have, lastly, investigated the radiation we obtained by substituting for the quartzmercury lamp a piece of amorphons quartz, heated by a Bunsen-flame. This radiation proved to be even of a somewhat smaller wave-length than that emitted by the Welsbach mantle under equal conditions. Less than two per cent. of it passed through black cardboard, and only ten per cent. through $2 \mathrm{~mm}$. of amorphous quartz. 
That the observed long-waved radiation is not emitted by the quartz walls is, therefore, an established fact, and it is highly probable that it originates in the luminous mercury vapour* .

But the question is not solved, whether we are dealing with a radiation of temperature or of luminosity. According to measurements of Messrs. Küch and Retschinsky $\dagger$, the mercury vapour of the quartz-mercury lamp possesses a teinperature which amounts to many thousand degrees. In this case, the observation of such long-waved pure temperature radiation is not impossible, if the radiating mercury vapour possesses strongly defined selective absorption in that spectral region.

The inain result of this investigation is the fact that heat rays of a wave-length of about $0.3 \mathrm{~mm}$. may be extracted from the radiation of the mercury-lamp in sufficient force to permit an investigation of their qualities. The infrared spectrum thereby sustains another enlargement of $1 \frac{1}{2}$ octaves.

\section{Proceedings of Learned Societies.}

\section{GEOLOGICAL SOCIETY.}

[Continued from p. 3:12.]

December 21st, 1910.-Prof. W. W. Watts, Sc.D., M.Sc., F.R.S., President, in the Chair.

THE following communication was read:-

'The Keuper Marls around Charnwood Forest.' By Thomas Owen Bosworth, B.A., B.Se., F.G.S.

The area tuder consideration comprises some 300 square miles, including the towns of Leicester, Loughborough, Coalville, and Hinckley. As has been shown by Prof. Watts, the Charnian rocks project through a mantle of Triassic deposits which once completely covered them. In numerous quarry-sections the relation of the Keuper to the pre-Cambrian rocks is well exposed.

The quarries generally have been opened in the summits of the more or less completely buried hills. A quarry is so worked that its outline follows the contour of the buried hill: consequently, the section presents but a dwarfed impression of the irregularity of the rock-surface. Nevertheless, considerable undulations are observed,

* Ir is, moreover, not quite out of the range of possibility that this long-waved radiation could consist of relatively very short Hertzian waves, which are produced by electric oscillations in small mercury drops. But it seems improbable that any condensation of mercury vapour would take place in the path of the current, $i$. e. in the hottest part of the tube.

$\dagger$ Küch \& Retschinsliy, Ann.d. Plys. xxii. p. 595 (1907). 